\title{
Physical Activity Levels and Mood State during COVID-19 Quarantine among the Kermanshah Population: A Cross-Sectional Online Survey Study
}

Mohammad Azizi

Razi University

Alireza Aghababa

Sport Sciences Research Institute

Rastegar Hoseini ( $\sim$ R.hoseini@razi.ac.ir)

Razi University https://orcid.org/0000-0001-8685-2471

Hadi Rohani

Sport Sciences Research Institute

Maghsoud Nabilpoor

Imam Khomeini International University

Research Article

Keywords: Physical Activity, Mood State, COVID-19

Posted Date: April 15th, 2021

DOI: https://doi.org/10.21203/rs.3.rs-397992/v1

License: (c) (1) This work is licensed under a Creative Commons Attribution 4.0 International License.

Read Full License 


\section{Abstract \\ Background}

One of the most important consequences of COVID-19 pandemic is anxiety and stress in the general population that can be reduced by regular physical activity. The aim of this study was to estimate the physical activity levels and mood state during covid-19 quarantine among the Kermanshah population.

\section{Methods}

In this cross-sectional study, using the purposeful random sampling method, a total of 2471 subjects ( $($ male $(n=1256)$ and female $(n=1215))$ were selected. To assess the physical activity level from physical activity questionnaire short form (IPAQ-SF) and mood state was measured by the abbreviated form of the Iranian version of the standard POMS questionnaire (Bill Morgan 1979). The descriptive statistic method (mean, standard deviation, and percent), deductive (Chi- square and Spearman's correlation) were used for analyzing the data.

\section{Results}

The results showed that a significant difference was observed between the number of sessions $(P=$ $0.001)$, intensity $(P=0.001)$, and duration of exercise $(P=0.001)$ before and during coronavirus. There are significant positive relationships between low $(r=0.93 ; P=0.001)$ and high $(r=0.673 ; P=0.034)$ levels of physical activity and negative mood state, and a positive relationship between moderate physical activity level $(r=0.82 ; P=0.001)$ and positive mood state.

\section{Conclusions}

It could be determined that the current quarantine has negatively affected the mood state. In general, to prevent COVID-19, regular physical activity is recommended under the health and safety protocols.

\section{Introduction}

On December 29, 2019, the Wuhan hospital, China, noticed unusual cases of patients with pneumonia.[1] However, the first case of the disease was observed on December 12.[1, 2] Further investigations showed that the disease originated in the seafood, poultry and alive animals market in Wuhan City, Hubei Province in China.[2] Afterward an unusual outbreak of pneumonia was reported to the World Health Organization on December 31. On January 1, 2020, the market was closed, and disinfected. After widespread speculation about the cause of this disease, the Chinese Center for Disease Control and Prevention finally confirmed the report published by the Wall Street Journal and on January 9, 2020, announced the novel coronavirus called COVID-19 as the cause of the disease.[3] 
Governments embrace health strategies to prevent the virus's spread until the vaccine would be developed. $[4,5]$ Healthy strategies and declare a state of quarantine were applied when observing the first COVID-19 cases. The promotion of social distancing modified the physical activity (PA) and life habits of the Iranian population.[6] All activities practiced in gyms, sports centers and swimming pools were suspended.[6, 7] Since access to public parks and gardens was prohibited athletes and amateurs were only allowed to practice near home while respecting the distance of at least one meter from other people and thus the practice of PA has been progressively subjected to limiting conditions.[8, 9] Although quarantine and socio-physical distancing are effective in decelerating the spread of the virus, they may have negative psychological and physiological effects on most people in the community that lead to nonconformity of health protocols.[10,11] Regular Exercise and physical activity improve physical fitness, mental health (reduce depression, anxiety, and aggression),[12] reduce the incidence of chronic diseases,[13] physical disabilities,[14] and enhances the immune system.[14] The ACSM has also recently identified physical activity as an effective factor in combating the complications and mortality of COVID19. $[10,15]$ However, studies show a decrease in the individual's physical activity level during the COVID19 epidemic. Due to the positive physiological-psychological effects, performing physical activity seems necessary in the quarantine in all uninfected individuals. $[16,17]$ The present study intends to investigate physical activity levels and quality of life during COVID-19 quarantine among the Kermanshah population.

\section{Methods}

\section{Study Design}

The present study is a quick, large cross-sectional online survey conducted using the WhatsApp Forms web survey platform (WhatsApp, Kermanshah, Iran).

\section{Procedure}

The online survey was anonymous and not attributable to the identity of the participants. An announcement, which included the link to the online survey, was published both on the All websites and communication networks of Kermanshah province. Moreover, using the snowball sampling recruitment method, the online survey was disseminated via social media such as Instagram, Telegram and shared with the personal contacts of the research group members and among the university students. Prior to the start of the questionnaire, the online survey form comprised a brief description of the study, its purpose and the declarations of anonymity and confidentiality. The Ethics Committees of the Sport Sciences Research Institute of Iran (Protocol Number: IR.SSRC.REC.1399.070) approved the study in conformity with the Declaration of Helsinki principles.

Participants included in the study completed the online questionnaire between the 28th of March to the 20th of May 2020. Participants were recruited during the COVID-19 quarantine in Iran, a period in which the measures taken by the government have limited the access to PA practices in all gyms, sports centers and swimming pools, and have prohibited any outdoor PA in public parks and gardens. [8, 9] A total of 
2471 subjects $(($ male $(n=1256)$ and female $(n=1215))$, both physically active and inactive, completed the online questionnaire. To minimize the impact of errors due to this type of data, we adopted a cleaning process which consisted of the following steps: removal of ineligible cases and of multiple submissions of the same respondent; identification and handling of meaningless data. The latter were represented by invalid responses to the questionnaire due to the respondents' reluctance to provide valid responses and the lack of internal consistency of responses. Data collection tools included Physical Activity Questionnaire (IPAQ) and Mood state was measured by Standard POMS questionnaire (Bill Morgan 1979). To manage this last point, a threshold/cutoff value was calculated according to the IPAQ scoring protocol, reported in the "Guidelines for Data Processing and Analysis of the International Physical Activity Questionnaire (IPAQ)-Short and Long Forms", under the constraint of consistency of responses (http://www.ipaq.ki.se).

\section{Questionnaire}

Since the questionnaire was administered to participants only once, the levels of PA for both conditions (before and during COVID-19) were assessed at the same time. The online self-reporting questionnaire consisted of 31 questions investigating the respondents' PA practice in terms of frequencies and durations of sitting, walking, moderate-intensity physical activities and vigorous-intensity physical activities. The questionnaire, reported in Appendix A, was divided into nine sections which included: (1) demographic data (questions 2 and 3); (2) anthropometric data (questions 4 and 5);(3) PA before the COVID-19 quarantine (questions 6 and 7); (4) information relating to employment and residence during COVID-19 quarantine (from question 8 to 13); (5) information (before and during the COVID-19 quarantine) relating to vigorous-intensity PA (from question 14 to 17); (6) moderate-intensity PA (from question 18 to 21); (7) walking activity (from question 22 to 25); (8) sedentary behaviors (questions 26 and 27); (9) additional information regarding the practice of PA during the COVID-19 quarantine (from question 28 to 31 ). The validity and reliability of this questionnaire has been measured and determined by other researchers and has been introduced as one of the appropriate tools to assess the PAL in epidemiological studies [18]. This questionnaire includes 5 main components of daily physical activity including type, frequency, intensity, duration, and total physical activity volume. To determine the PAL, the total score related to the frequency, intensity, duration and total physical activity volume is multiplied by the scaled score for different types of physical activity and is obtained between 4 and 100. Then the PAL is divided into three categories: high (65 and above), sufficient (64 - 36), and inactive (35 and below).

Mood state was measured by Standard POMS questionnaire (Bill Morgan 1979) was translated and modified in some of the questions, and validity and correlation by the test - this test of reliability obtained (Cronbach Alpha 87\%). POMS questionnaire includes six mental states: Tension, depression, vitality, anger, fatigue, and confusion.[19] The answers consisted of: not at all, a little, moderately, quite a lot, and extremely, Scored from zero to four, respectively. The subjects were asked to express their current and last week mood state. Evidence shows high reliability and validity for this questionnaire [20].

\section{Data Analysis}


All statistical analyses were performed using the SPSS statistical software (version 21; SPSS Inc., Chicago, IL, USA) was used at a significant level of $P<0.05$. The Kolmogorov-Smirnov test was used for evaluating the normality of distribution. The descriptive statistic method (mean, standard deviation, and percent), deductive (Chi- square and Spearman's correlation) were used for analyzing the data.

\section{Results}

The mean \pm SD of demographic indices among the subjects are presented in Table 1 . 
Table 1

Mean \pm SD demographic indices among the subjects

\begin{tabular}{|c|c|c|}
\hline Variable & Male $(n=1256)$ & Female $(n=1215)$ \\
\hline Age & $27.87 \pm 5.011$ & $25.12 \pm 6.49$ \\
\hline Married & 823 & 595 \\
\hline Single & 405 & 600 \\
\hline Divorced & 28 & 20 \\
\hline Urban & 597 & 544 \\
\hline Rural & 544 & 524 \\
\hline Suburbs & 115 & 147 \\
\hline Positive mental states & 302 & 404 \\
\hline Negative mental states & 954 & 811 \\
\hline Getting infected & 110 & 83 \\
\hline No infection & 381 & 269 \\
\hline Not knowing & 765 & 863 \\
\hline Observance & 289 & 730 \\
\hline No observance & 967 & 485 \\
\hline \multicolumn{3}{|l|}{ Education rate } \\
\hline High school & 195 & 145 \\
\hline Diploma & 177 & 196 \\
\hline Associate Degree & 346 & 289 \\
\hline BSc & 416 & 417 \\
\hline MSc & 105 & 156 \\
\hline $\mathrm{PhD}$ & 17 & 12 \\
\hline \multicolumn{3}{|l|}{ Job Status } \\
\hline Manual worker & 137 & 29 \\
\hline Employee & 76 & 33 \\
\hline Student & 178 & 260 \\
\hline Part-time & 163 & 99 \\
\hline Self-employed & 256 & 88 \\
\hline
\end{tabular}




\begin{tabular}{|lll|}
\hline Variable & Male $(n=1256)$ & Female $(n=1215)$ \\
\hline Unemployed & 446 & 706 \\
\hline
\end{tabular}

Table 2 showed that a significant difference was observed between the number of sessions, intensity, and duration of exercise before and during coronavirus; Based on these results, the number, intensity, and duration of training sessions during coronavirus showed a significant decrease. 
Table 2

Number, intensity, and duration of sessions before and during the coronavirus between subjects

\begin{tabular}{|c|c|c|c|c|}
\hline Number of practice sessions & $\begin{array}{l}\text { Before the } \\
\text { coronavirus }\end{array}$ & $\begin{array}{l}\text { During the } \\
\text { coronavirus }\end{array}$ & $\begin{array}{l}\text { Chi-Squared } \\
\text { Test }\end{array}$ & $\begin{array}{l}\text { P- } \\
\text { Value }\end{array}$ \\
\hline Never & 134 & 274 & 2153.023 & $0.001 *$ \\
\hline one day & 219 & 214 & & \\
\hline Two Days & 255 & 305 & & \\
\hline Three Days & 522 & 354 & & \\
\hline Four Days & 328 & 172 & & \\
\hline Five Days & 138 & 147 & & \\
\hline Six Days & 127 & 80 & & \\
\hline Seven Days & 329 & 312 & & \\
\hline Sometimes & 419 & 613 & & \\
\hline Total & 2471 & 2471 & & \\
\hline $\begin{array}{l}\text { The intensity of Training } \\
\text { Sessions }\end{array}$ & & & 539.906 & $0.001 *$ \\
\hline Low & 248 & 699 & & \\
\hline Moderate & 1041 & 1352 & & \\
\hline High & 997 & 349 & & \\
\hline Very High & 185 & 71 & & \\
\hline Total & 2471 & 2471 & & \\
\hline $\begin{array}{l}\text { Duration of Training } \\
\text { Sessions }\end{array}$ & & & 479.021 & $0.001 *$ \\
\hline Less than 30 minutes & 519 & 839 & & \\
\hline More than 30 minutes & 1952 & 1632 & & \\
\hline Total & 2471 & 2471 & & \\
\hline
\end{tabular}

The results of Table 3 showed there is a significant negative relationship between positive mood and low physical activity levels $(r=-0.73 ; P=0.002)$, and a significant positive relationship between positive mood and the moderate physical activity levels $(r=0.82 ; P=0.001)$; Also, there was no significant relationship between positive mood and high physical activity levels $(r=0.067 ; P=0.331)$. Besides of these results, 
there is a significant positive relationship between negative mood with low levels of physical activity $(r=$ $0.93 ; P=0.001)$ and high levels of physical activity $(r=0.673 ; P=0.034)$; there is a significant negative relationship between negative mood and moderate physical activity levels $(r=-0.87 ; P=0.001)$.

Table 3

The relationship between the physical activity levels and mental states

\begin{tabular}{|c|c|c|c|}
\hline \multirow[t]{2}{*}{ Mental states } & \multicolumn{3}{|c|}{ Physical activity Levels } \\
\hline & Low & Moderate & High \\
\hline \multirow[t]{2}{*}{ Positive Mood } & $r=-0.73$ & $r=0.82$ & $r=0.321$ \\
\hline & $P=0.002^{¥}$ & $P=0.001^{\sharp}$ & $P=0.331$ \\
\hline \multirow[t]{2}{*}{ Negative Mood } & $r=0.93$ & $r=-0.87$ & $r=0.673$ \\
\hline & $P=0.001^{\sharp}$ & $P=0.001^{\#}$ & $P=0.034^{¥}$ \\
\hline
\end{tabular}

\section{Discussion}

The results of the present study showed that the intensity of exercise, duration, and the number of sessions per week significantly decreased during the COVID-19 outbreak compared to before. Although such results were not unexpected, the fear of getting infected may have affected various activities and limited the social activities, and limited exercise and physical activity and even closed the clubs after the outbreak of the virus. Additionally, these changes in lifestyle and not having a fun leisure time, led to increment in stress and anxiety level in society. However, the closure of physical activities is the cause of many diseases, exacerbation of obesity, and motor poverty.[21] Therefore, health researchers recommend that people do workouts differently to strengthen the immune system.[21, 22] As sports clubs have been restricted and many closed to prevent the spread of the coronavirus, the possibility of attending clubs has been very limited.[23, 24] Therefore, to prevent obesity and other consequences of a sedentary lifestyle, home exercises and increased physical activities such as walking might be beneficial.[21,25]

Also, the results of the present study showed that the moderate levels of exercise activity significantly reduce the negative mood states caused by the fear of COVID-19 and increase the positive mood states. Being sedentary caused a significant increase in negative mood states and a significant decrease in positive mood states. In the present study, a high level of physical activity was not only significantly related to increased positive mood states; but also was significantly related to increased negative mood states. 
In general, physical activity is one of the most important providers of physical and mental health. Exercise can improve the body's fight against infection by strengthening the immune system.[23] According to the results of the studies, intense and competitive exercise is not suitable in these conditions and can reduce the body's immune response and lead to a higher risk of infection with coronavirus.[26, 27] Most studies have emphasized avoiding long term sitting and sedentary lifestyle, which is very common, especially in young people, by wasting too much time on social media and networks.[26, 28] In addition to improving the function and capacity of the immune system, physical activity can help reduce anxiety and stress, improve mood, control many underlying diseases such as diabetes, hypertension, cardiovascular disease.[21, 29] Healthy adults should have at least 30 minutes a day of moderateintensity exercise.[30]

In general, regarding to the profoundly positive impacts of the physical activity on lowering stress and anxiety, it is necessary to be physically active during the corona outbreak. Although, the healthy protocols including disinfecting sports equipment with alcohol, and washing hands with soap and water should be considered.

\section{Declarations}

\section{Authors' contributions}

Mohammad Azizi contributed to the conception and design of the study, the acquisition, analysis, and interpretation of data, and drafting and revising critically the article for important intellectual content. Alireza Aghababa contributed to the acquisition, analysis, and interpretation of data. Rastegar Hoseini contributed to the acquisition, analysis, and interpretation of data. Hadi Rohani contributed to the acquisition, analysis, and interpretation of data. Maghsoud Nabilpoor contributed to drafting and revising critically the article for important intellectual content. All authors approved the final version of the article.

Funding: The author(s) received no specific funding for this work.

\section{Availability of data and materials}

The datasets used and/or analysed during the current study are available from the corresponding author on reasonable request.

\section{Ethics approval and consent to participate.}

The Ethics Committees of the Sport Sciences Research Institute of Iran (Protocol Number: IR.SSRC.REC.1399.070) approved the study in conformity with the Declaration of Helsinki principles.

\section{Competing interests}

The authors declare no competing interests.

\section{Conflict of interest}


The authors report no conflicts of interests.

\section{References}

1. Javanian M, Masrour-roudsari J, Bayani M, Ebrahimpour S. Coronavirus disease 2019 (COVID-19): What we need to know. Caspian J Intern Med. 2020;11:235-6.

2. Mohseni Afshar Z, Ebrahimpour S, Javanian M, Vasigala VR, Masrour-Roudsari j, Babazadeh A. Vital role of chest CT in diagnosis of coronavirus disease 2019 (COVID-19). Caspian J Intern Med. 2020;11:244-9.

3. Wu Z, McGoogan JM. Characteristics of and important lessons from the coronavirus disease 2019 (COVID-19) outbreak in China: summary of a report of 72314 cases from the Chinese Center for Disease Control and Prevention. Jama. 2020;323:1239-42.

4. Sohrabi C, Alsafi Z, O'Neill N, Khan M, Kerwan A, Al-Jabir A, losifidis C, Agha R. World Health Organization declares global emergency: A review of the 2019 novel coronavirus (COVID-19). International Journal of Surgery 2020.

5. Sahin AR, Erdogan A, Agaoglu PM, Dineri Y, Cakirci AY, Senel ME, Okyay RA, Tasdogan AM. 2019 novel coronavirus (COVID-19) outbreak: a review of the current literature. EJMO. 2020;4:1-7.

6. Tuite AR, Bogoch II, Sherbo R, Watts A, Fisman D, Khan K. Estimation of coronavirus disease 2019 (COVID-19) burden and potential for international dissemination of infection from Iran. Ann Intern Med. 2020;172:699-701.

7. Shahriarirad R, Khodamoradi Z, Erfani A, Hosseinpour H, Ranjbar K, Emami Y, Mirahmadizadeh A, Lotfi M, Yeganeh BS, Nejad AD. Epidemiological and clinical features of 2019 novel coronavirus diseases (COVID-19) in the South of Iran. BMC Infect Dis. 2020;20:1-12.

8. Shah SGS, Farrow A. A commentary on "World Health Organization declares global emergency: A review of the 2019 novel Coronavirus (COVID-19)". International journal of surgery (London England). 2020;76:128.

9. Sabino-Silva R, Jardim ACG, Siqueira WL. Coronavirus COVID-19 impacts to dentistry and potential salivary diagnosis. Clin Oral Invest. 2020;24:1619-21.

10. Zhu W. Should, and how can, exercise be done during a coronavirus outbreak? An interview with Dr. Jeffrey A. Woods. Journal of Sport Health Science. 2020;9:105.

11. Phelan AL, Katz R, Gostin LO. The novel coronavirus originating in Wuhan, China: challenges for global health governance. Jama. 2020;323:709-10.

12. Rodriguez-Ayllon M, Cadenas-Sanchez C, Estevez-Lopez F, Munoz NE, Mora-Gonzalez J, Migueles JH, Molina-Garcia P, Henriksson H, Mena-Molina A, Martinez-Vizcaino V. Role of physical activity and sedentary behavior in the mental health of preschoolers, children and adolescents: a systematic review and meta-analysis. Sports medicine 2019:1-28.

13. Marques A, Peralta M, Sarmento H, Martins J, González Valeiro M. Associations between vigorous physical activity and chronic diseases in older adults: a study in 13 European countries. Eur J Pub 
Health. 2018;28:950-5.

14. Bloemen M, Van Wely L, Mollema J, Dallmeijer A, de Groot J. Evidence for increasing physical activity in children with physical disabilities: a systematic review. Developmental Medicine Child Neurology. 2017;59:1004-10.

15. Chen P, Mao L, Nassis GP, Harmer P, Ainsworth BE, Li F. Wuhan coronavirus (2019-nCoV): The need to maintain regular physical activity while taking precautions. Journal of sport health science. 2020;9:103.

16. Qian J, McDonough DJ, Gao Z. The Effectiveness of Virtual Reality Exercise on Individual's Physiological, Psychological and Rehabilitative Outcomes: A Systematic Review. International Journal of Environmental Research Public Health. 2020;17:4133.

17. Cortis C, Tessitore A, D’Artibale E, Meeusen R, Capranica L. Effects of post-exercise recovery interventions on physiological, psychological, and performance parameters. Int J Sports Med. 2010;31:327-35.

18. Cho M-HJJopts. Preliminary reliability of the five item physical activity questionnaire. 2016, 28:3393-3397.

19. Morfeld M, Petersen C, Krüger-Bödeker A, Von Mackensen S, Bullinger M. The assessment of mood at workplace-psychometric analyses of the revised Profile of Mood States (POMS) questionnaire. GMS Psycho-Social Medicine 2007, 4.

20. Curran SL, Andrykowski MA, Studts JLJPa. Short form of the profile of mood states (POMS-SF): psychometric information. 1995, 7:80.

21. Mattioli AV, Sciomer S, Cocchi C, Maffei S, Gallina S. Quarantine during COVID-19 outbreak: changes in diet and physical activity increase the risk of cardiovascular disease. Nutrition Metabolism Cardiovascular Diseases. 2020;30:1409-17.

22. Kruk J, Aboul-Enein HY, Kładna A, Bowser JE. Oxidative stress in biological systems and its relation with pathophysiological functions: the effect of physical activity on cellular redox homeostasis. Free Radic Res. 2019;53:497-521.

23. Kandola A, Ashdown-Franks G, Hendrikse J, Sabiston CM, Stubbs B. Physical activity and depression: towards understanding the antidepressant mechanisms of physical activity. Neuroscience Biobehavioral Reviews. 2019;107:525-39.

24. Jakobsson J, Malm C, Furberg M, Ekelund U, Svensson M. Physical Activity During the Coronavirus (COVID-19) Pandemic: Prevention of a Decline in Metabolic and Immunological Functions. Frontiers in Sports Active Living. 2020;2:57.

25. Shephard RJ. Can regular physical activity prevent obesity? 3: Empirical longitudinal evidence of its efficacy. The Health Fitness Journal of Canada. 2019;12:3-92.

26. Simpson RJ, Campbell JP, Gleeson M, Krüger K, Nieman DC, Pyne DB, Turner JE, Walsh NP. Can exercise affect immune function to increase susceptibility to infection? Exerc Immunol Rev. 2020;26:8-22. 
27. Aktuğ ZB, İri R, Demir NA. COVID-19 immune system and exercise. Journal of Human Sciences. 2020;17:513-20.

28. da Silveira MP, da Silva Fagundes KK, Bizuti MR, Starck É, Rossi RC. e Silva DTdR: Physical exercise as a tool to help the immune system against COVID-19: an integrative review of the current literature. Clinical and experimental medicine 2020:1-14.

29. Cho L, Davis M, Elgendy I, Epps K, Lindley KJ, Mehta PK, Michos ED, Minissian M, Pepine C, Vaccarino V. Summary of Updated Recommendations for Primary Prevention of Cardiovascular Disease in Women: JACC State-of-the-Art Review. J Am Coll Cardiol. 2020;75:2602-18.

30. Piercy KL, Troiano RP, Ballard RM, Carlson SA, Fulton JE, Galuska DA, George SM, Olson RD. The physical activity guidelines for Americans. Jama. 2018;320:2020-8.

\section{Appendix}

Appendix $A$ is not available with this version. 